This is the version of the article accepted for publication in The European Journal of Development Research 28 (4),

521-535 published by Springer. Published version available from:

http://link.springer.com/article/10.1057/ejdr.2015.86

Accepted version downloaded from SOAS Research Online: http://eprints.soas.ac.uk/23439/

\title{
The electrification-malaria nexus: the case of rural Uganda
}

\begin{abstract}
Sub-Saharan countries are facing multiple simultaneous challenges that include both the need to increase access to electricity and to combat morbidity and mortality caused by malaria. This study is the first to explore the nexus between electrification and malaria incidence using a country-wide representative household level data. The focus is on rural Uganda. Despite the fact that data used in this analysis come from a multi topic survey and therefore do not include the ideal indicators for a malaria related study, we do find evidence that household members having access to electricity are more likely to experience malaria. Our interpretation is that electric light attracts malaria vectors and that lifestyle changes associated with outdoor lighting increase humans' exposure to the vectors. Our findings suggest that the electrification process in Uganda should be complemented by anti-malaria strategies.
\end{abstract}

JEL Codes: electrification; malaria; Uganda; household data, probit analysis. 
This is the version of the article accepted for publication in The European Journal of Development Research 28 (4), 521-535 published by Springer. Published version available from:

http://link.springer.com/article/10.1057/ejdr.2015.86

Accepted version downloaded from SOAS Research Online: http://eprints.soas.ac.uk/23439/

\section{Introduction}

Rural electrification is a precondition for improving many aspects of the lives of the members of a household and is a development priority for many Sub-Saharan countries (e.g. World Bank, 2008). Artificial lighting brings a number of benefits ranging from extended hours for businesses, which in turn boosts income opportunities, to allowing increased study time for children, greater security, and time savings if compared with collecting fuel-wood. Furthermore, electricity can provide household members with access to television and radio, giving them the opportunity to follow news, films, cartoons and soap operas, which have a number of impacts on the empowerment of women (Grimm et al., 2015; Chong and La Ferrara, 2009). The consequences of using cleaner sources of energy for cooking are remarkable for both children's and adults' health and translate into a marked decrease in the incidence of respiratory diseases and eye infections (e.g. Torres-Duque et al., 2007). Notwithstanding these known benefits, the full impact of these sources of energy is still being investigated and it is difficult to draw solid conclusions across countries and scales (Pellegrini and Tasciotti, 2012). While we acknowledge beforehand the overall positive consequences of using electricity for lighting, our research focuses on some little-studied (potential) negative impacts by exploring the link between the use of electricity and the incidence of malaria at the household-member level. In this empirical study we look at the case of Uganda where the incidence of malaria is very high with 12 million suspected malaria cases and 6,296 malaria attributed deaths in 2009 (World Health Organization, 2012). At the same time, 
This is the version of the article accepted for publication in The European Journal of Development Research 28 (4), 521-535 published by Springer. Published version available from:

http://link.springer.com/article/10.1057/ejdr.2015.86

Accepted version downloaded from SOAS Research Online: http://eprints.soas.ac.uk/23439/

the current electrification rate in Uganda is one of the lowest in the sub-Saharan countries with just $9 \%$ of households being connected to the grid or using solar panels (International Energy Agency, 2011). To tackle the situation, Uganda is investing extensively in electrification as a way to foster growth and promote the startup of domestic businesses (Ministry of Energy and Mineral Development, 2002; Rural Electrification Agency, 2006).

Although the link between modern energy sources and malaria has not been thoroughly investigated, there have been studies focusing on some of the mechanisms potentially underlying this relationship. On one hand, artificial light is a powerful insect attractant (Barghini and de Medeiros, 2010) and both entomologists and epidemiologists use light traps to capture insects (Shiff et al., 2008). On the other hand, artificial light is also a direct indicator of economic development, and lighted areas in night-time satellite images coincide with areas of the world with higher levels of socio-economic development (Noor et. al., 2008). In turn, changes associated with economic development can alter lifestyles, access to information, and behaviour related to prevention, etc. As an example of these changes, night lighting increases outdoor activities and hence exposure to malaria vectors, but electricity can also increase access to mass media and to anti-malaria campaigns, which in turn can induce households to undertake preventive measures. Electricity and, similarly, liquid propane gas (LPG) used for cooking replaces biomass and reduces indoor smoke, resulting in substantially improved indoor air quality. However, smoke can also function as an insect repellant 
This is the version of the article accepted for publication in The European Journal of Development Research 28 (4), 521-535 published by Springer. Published version available from:

http://link.springer.com/article/10.1057/ejdr.2015.86

Accepted version downloaded from SOAS Research Online: http://eprints.soas.ac.uk/23439/

and improved air quality can concur with increased density of malaria vectors. Here we just mentioned some of the channels linking energy sources and malaria occurrence; it appears that modern energy sources can have positive as well as negative effects and the issue of the overall effect is an empirical question. This is the first study conducted on the linkage between the use of electricity and malaria incidence at the individual level based on a large dataset of households. The data was collected in rural Uganda.

It is important to stress from the onset that the purpose of this study is not to discourage rural electrification projects or to question the benefits made possible by access to artificial lighting, but rather to explore the potential link between electricity and malaria. If, as our findings suggest, such a link exists, the nexus should be assessed with data from malaria and electricity specific surveys. Meanwhile, electrification projects should be accompanied by anti-malaria strategies, such as the provision of screens and treated bed-nets, aimed at eliminating/reducing this unintended consequence of access to electricity.

Section 2 presents the main studies on the link between electricity and malaria and explores the potential channels through which electrification can affect malaria incidence. Section 3 provides an overview of the electrification process in Uganda and describes the severity of malaria incidence. Section 4 describes the main features of the dataset; furthermore it highlights the main data problems and how they are handled. The empirical strategy and the regression results are presented in Section 5. Conclusion and policy implications are drawn in Section 6. 
This is the version of the article accepted for publication in The European Journal of Development Research 28 (4), 521-535 published by Springer. Published version available from:

http://link.springer.com/article/10.1057/ejdr.2015.86

Accepted version downloaded from SOAS Research Online: http://eprints.soas.ac.uk/23439/

\section{Is there a link between electricity and malaria? Evidence from the literature}

Despite the seriousness of malaria incidence in many countries, its potential association with electrification and the increasing number of electrification projects being undertaken in many areas of Africa, Asia and Latin America, there is only circumstantial evidence of the relationship between electrification and malaria. ${ }^{1}$

We model the association between electrification and malaria according to the following equation:

$$
M I=f(\text { vector density, exposure }),
$$

where $M I$ indicates Malaria Incidence, vector density stands for the concentration of malaria vectors in the living space and exposure refers to the amount of time household members spend in places where malaria vectors are present. Essentially, this formula states that the incidence of malaria is a function of how many vectors are present in the exposure area and how much time humans are exposed to malaria vectors. We now discuss how electricity can affect vector density and then look at exposure.

\section{Vector Density}

It has been argued that mosquitoes are attracted to light (Barghini and de Medeiros, 2010; Barret et al., 1973; Barret et al., 1974), and malaria vectors are captured using

\footnotetext{
${ }^{1}$ In contrast, the relation between access to electricity and the occurrence of Chagas disease and leishmaniasis, has been studied. Chagas disease is commonly transmitted to humans and other mammals by an insect vector while leishmaniasis is a disease caused by protozoan parasites that belong to the genus Leishmania and is transmitted by the bite of certain species of sand fly. The occurrence of these two types of disease has been proven to increase in electrified areas (Barghini and de Medeiros, 2010).
} 
This is the version of the article accepted for publication in The European Journal of Development Research 28 (4), 521-535 published by Springer. Published version available from:

http://link.springer.com/article/10.1057/ejdr.2015.86

Accepted version downloaded from SOAS Research Online: http://eprints.soas.ac.uk/23439/

suction light traps with heat or carbon dioxide bait (Jawara et al., 2008; Lee et al., 2009;

Suárez-Mutis et al. 2009; Tirados at al., 2006). This suggests that night lighting can increase the indoor density of malaria vectors.

Other examples pointing to a positive correlation between vector density and electricity come from recent studies. Yamamoto et al. (2010), working with household data collected in Burkina Faso, found that living in a place where electricity is available is associated with an increased risk of malaria, holding constant other variables. They motivate their finding with the fact that the use of biomass for cooking and lighting produces smoke that might prevent insects from biting. Similar evidence comes from an experiment done in a rural village in the Wosera area, Papua New Guinea (Paul et al., 1995). Insect repelling effects were associated with the burning of several species of plants in Kenya (Seyoum et al., 2002).

The discussion on whether smoke is a mosquito repellent is still open and recent experiments have produced contrasting results. Biran et al. (2007) reviewed the literature related to the effect of smoke on mosquitoes, concluding that there is no consistent evidence that smoke produced by charcoal and fire-wood provides protection from malaria mosquitoes. Furthermore, using biomass for cooking and lighting inside the house could indirectly increase the risk of infection as house ventilation, aimed at reducing the level of indoor smoking, also provides opportunities for mosquitoes to enter the house. Nevertheless, the result of an experiment done in Sri Lanka found that the risk of malaria is significantly lower in households using 'traditional fumigants' (van 
This is the version of the article accepted for publication in The European Journal of Development Research 28 (4), 521-535 published by Springer. Published version available from:

http://link.springer.com/article/10.1057/ejdr.2015.86

Accepted version downloaded from SOAS Research Online: http://eprints.soas.ac.uk/23439/

der Hoek et al., 1998). ${ }^{2}$ A subsequent experiment contradicted the previous findings (Konradsen et al., 2003) while other authors argue that smoke will inhibit the mosquitoes from biting, but only during limited hours (Barnes et al., 2004; Ezzati et al., 2000).

\section{Exposure}

Electrification changes lifestyles in a number of ways and, in turn, these changes can affect exposure. Barghini and de Medeiros (2010) provide evidence of how habits changed in some communities living in isolated areas of the Amazon. In particular, the authors show that electricity allows household members to spend more time outside the house in the hours when vectors are more active: just after sunset and in the first hours of the evening.

Similar patterns have been noticed by authors observing behavioural changes that include enhanced social interaction taking place outdoors especially after sunset (e.g. Winther, 2011). Also larger social events - such as sport activities - can now be practised outdoors in the evening thanks to artificial lighting and a major impact of electrification is to alter the 'light and day input' through controlling artificial light during solar darkness (Wright et al., 2005; Louzada et al., 2004). In fact, some authors have already argued that increased time spent outside the house during evening and night hours might have caused an increase in malaria infection based on evidence from the

\footnotetext{
${ }^{2}$ Many communities living in rural areas where malaria is endemic use aromatic smokes in addition to wood fuel, i.e. traditional fumigants, to deter mosquitoes. In rural Gambia, tree bark combined with synthetic perfumes (locally known aschurai) reduced the number of mosquitoes entering a room even though the incidence of malaria is about the same. Traditional fumigants in Sri Lanka are believed to decrease malaria.
} 
This is the version of the article accepted for publication in The European Journal of Development Research 28 (4), 521-535 published by Springer. Published version available from:

http://link.springer.com/article/10.1057/ejdr.2015.86

Accepted version downloaded from SOAS Research Online: http://eprints.soas.ac.uk/23439/

Salomon Islands (Taylor, 1997). The relation between being outdoors and exposure to malaria is further underscored by studies that compare the presence of vectors outdoors and indoors. Gil et al. (2007) concluded that the risk of infective bites is approximately 5 times higher outside than inside the houses in Vila Candelária and about 3 to 5 times greater in Bate Estaca, both towns located in the Brazilian Amazon. Similar evidence emerges from investigations carried out in rural Vietnam and rural Peru (Erhart et al., 2004).

Nevertheless, electricity can also change the behaviour of household members in ways that reduce exposure to malaria vectors. A stream of studies points out that households in electrified areas can achieve a lower incidence of malaria; mass media such as radio and television represent an important vehicle to promote awareness and encourage non-risk behaviour (Thang et al., 2008; Tsuyuoka et al., 2010). The relationship between access to mass media and malaria is confirmed by a case study on the determinants of malaria morbidity in some provinces of Southern Iran. The study highlights that the lack of accessibility to television and the exclusion of educational programmes raise the risk of malaria by 1.5 times compared to other villages. Similar effects were identified for radio access (Asl et al., 2003).

In summary, from the existing literature we know that electrification can have both beneficial and negative effects in relation to malaria incidence and the overall effect is an empirical question. This study provides the first attempt to find an answer to this 
This is the version of the article accepted for publication in The European Journal of Development Research 28 (4), 521-535 published by Springer. Published version available from:

http://link.springer.com/article/10.1057/ejdr.2015.86

Accepted version downloaded from SOAS Research Online: http://eprints.soas.ac.uk/23439/

question by analyzing a large sample of households in a country where malaria incidence is high and electrification is on the rise.

\section{Malaria incidence and electrification in Uganda: the state of affairs}

On April 25, 2011, the malaria community marked the fourth 'World Malaria Day'; malaria is considered to be one of the world's most important public health concerns, responsible for over a million deaths and up to 500 million clinical cases each year. ${ }^{3}$

In the case of Uganda, malaria is one of the most serious diseases and even though some progress in terms of prevention has been made in the last years - e.g. the share of households with at least one bed-net has increased by more than a factor of 4 in the period from 2000 to 2011 - the share of the population at risk of malaria is still extremely high and the number of reported malaria cases and malaria related deaths has increased (World Health Organization, 2010). Malaria is still a leading cause of morbidity and mortality and accounts for 25 to $40 \%$ of visits to health facilities, 15 to $20 \%$ of all hospitalisations and 9 to $14 \%$ of all inpatient deaths. Approximately half of all deaths among hospitalised children are attributed to malaria (PMI, 2012). Reported malaria cases have constantly increased in Uganda from 8.8 million cases in 2005 to 11.8 million cases in 2011 and mortality rates caused by malaria are among the highest in the world with 8,000 (6,000) reported malaria deaths in 2010 (2011) (WHO, 2012). ${ }^{4}$ A very

\footnotetext{
${ }^{3}$ See the website http://www.rbm.who.int/worldmalariaday/ accessed on February the $23^{\text {rd }}, 2012$.

${ }^{4}$ Various factors might however be responsible for the increase in the reported malaria cases and malaria deaths: the rapid population growth, the presence of new health facilities which have guaranteed easier access to public health services for the population and therefore better and more complete reporting; hence, due to incompleteness or inconsistency of reporting, it is extremely challenging to make a reliable assessment of malaria trends (WHO, 2012).
} 
This is the version of the article accepted for publication in The European Journal of Development Research 28 (4), 521-535 published by Springer. Published version available from:

http://link.springer.com/article/10.1057/ejdr.2015.86

Accepted version downloaded from SOAS Research Online: http://eprints.soas.ac.uk/23439/

high percentage of people, $88 \%$, are exposed to moderate to very high malaria

transmission risk with children under the age of 5 and pregnant women being considered the most biologically vulnerable population groups (WHO, 2012). ${ }^{5}$

Notwithstanding the severity and the high incidence of malaria in the country, Uganda has benefitted with another 16 countries from the President's Malaria Initiative (PMI), a 1.265 billion dollar, US led project (UNDP, 2011). The PMI efforts have been tangible if taking into consideration some malaria-related indicators (e.g. the number of households, children and pregnant women using bed nets, Table 1).

Table 1: key results from two subsequent nationwide household surveys

\begin{tabular}{|c|c|c|c|}
\hline Malaria Indicators in Uganda & PMI Baseline (DHS 2006) & MIS 2009 & DHS 2011 \\
\hline All-cause mortality rate in children under five & $137 / 1,000$ & $\mathrm{n} / \mathrm{a}$ & $\mathrm{n} / \mathrm{a}$ \\
\hline Proportion of households with at least one bed nets (in \%) & 16 & 47 & 60 \\
\hline $\begin{array}{l}\text { Proportion of children under five years old who slept under } \\
\text { an ITN the previous night (in \%) }\end{array}$ & 10 & 33 & 42 \\
\hline $\begin{array}{l}\text { Proportion of pregnant women who slept under an ITN the } \\
\text { previous night (in \%) }\end{array}$ & 10 & 44 & 46 \\
\hline Proportion of women who received two or more doses of & 16 & 32 & 36 \\
\hline
\end{tabular}

Notes: 'ITN' stands for insecticide treated bed nets and 'IPTp' for intermittent preventive treatment in pregnancy.

'DHS' data refer to the 'Demographic health survey' and 'MIS' refers to the 'Malaria indicator survey'.

Source: UNDP, 2011.

There are a number of reasons why Uganda is still marked by a high incidence of malaria: during the past 30 years the increase in the area of wetlands under cultivation and other man-made locations, such as brick pits or fish ponds, has created new breeding sites for malaria vectors (Ugandan Ministry of Health, 2005), At the same time poor environmental sanitation in general and massive deforestation in particular are also associated with a surge in breeding sites.

\footnotetext{
${ }^{5}$ Children are the ones contributing the most to the malaria-related mortality (approximately between 70,000 and 100,000 annually world-wide, a death toll that far exceeds that of HIV/AIDS; Lynch et al., 2010).
} 
This is the version of the article accepted for publication in The European Journal of Development Research 28 (4), 521-535 published by Springer. Published version available from:

http://link.springer.com/article/10.1057/ejdr.2015.86

Accepted version downloaded from SOAS Research Online: http://eprints.soas.ac.uk/23439/

We note that the high incidence of malaria coincides with the rising number of electrification projects taking place in the country. With the support of several donors and under the supervision of the Uganda Electricity Board, the organization responsible for supplying electrical power, many electrification projects are underway in various areas of the country. The Kisiizi Project has installed mini grids in the Rukungiri district using electricity from a small hydro plant and several grid extension projects have started in other districts (Fort Portal, Bundibugyo, Nyahuka, Rugombre and Kyenjojo). With the support of Japan, a grid extension is under construction in the south of the country and in the same area, under World Bank funding, a new electricity line has been put in place. Japan is also considering constructing small hydropower projects in some other rural sites. These projects have been initiated in Uganda with the intention of substantially increasing electricity penetration in rural areas (International Energy Agency, 2011).

\section{Data description and summary statistics}

The following analysis is based on data from 'The Uganda National Household Survey, 2009-2010' for which 6,775 households were surveyed. ${ }^{6}$ Almost $82 \%$ of the interviewed households are in rural villages while the remaining $18 \%$ are in urban areas. Heads of households were asked a number of questions: e.g. condition of the housing, main source of energy for cooking and lighting, food and non-food consumption, information

\footnotetext{
${ }^{6}$ For more information on the survey, please refer to the website:

http://iresearch.worldbank.org/PovcalNet/doc/UGA.htm lastly accessed 14/01/2014.
} 
This is the version of the article accepted for publication in The European Journal of Development Research 28 (4),

521-535 published by Springer. Published version available from:

http://link.springer.com/article/10.1057/ejdr.2015.86

Accepted version downloaded from SOAS Research Online: http://eprints.soas.ac.uk/23439/

on assets, etc., while other questions were addressed to each household member. In particular, the sections with questions regarding educational attainments, income profiles and health status, the core of our analysis, were asked at the individual household member level (36,432 in total, 31,085 of whom were living in rural areas).

Although our data come from a multi-purpose survey not focusing specifically on malaria related issues, there are, nevertheless, several questions related to health problems. Each individual is asked whether s/he suffered from any of the listed illnesses in the past 30 days (i.e. malaria among others), whether the individual had consulted a health practitioner (doctor, nurse, pharmacist or traditional healer) for the problem s/he had had, the reason why s/he did not see a health practitioner, how far the practitioner is located (in terms of distance) from the household residence and whether the individual had taken any medicine. This multi-purpose survey includes a number of other variables which can be used as controls for the empirical analysis: house ownership, education of the head of the household, incomes of household members, condition of the dwelling, type of toilet used and geographical variables.

The fact that we use data on malaria incidence from a multi-purpose survey might throw some doubt on the quality of the health data. In particular, the respondents' awareness regarding a number of illnesses and particularly malaria might not be very accurate. However, we are confident that the malaria-related data represent a reasonable approximation to the actual situation since several studies carried out in rural Uganda show that household members, both male and female, know how malaria is 
This is the version of the article accepted for publication in The European Journal of Development Research 28 (4), 521-535 published by Springer. Published version available from:

http://link.springer.com/article/10.1057/ejdr.2015.86

Accepted version downloaded from SOAS Research Online: http://eprints.soas.ac.uk/23439/

transmitted, the treatments when malaria is suspected and how to recognized malaria symptoms that include fever, headache, vomiting, diarrhea, tiredness, sweating, convulsions, paleness, weight loss and dehydration (Kengeya-Kayondo et al., 2004; Nuwaha, 2002). ${ }^{7}$ In any case, we acknowledge that we cannot exclude a margin of measurement error in the dependent variable that will include also some cases of malaria-like diseases. We do note that such measurement error is bound to decrease the statistical significance of the coefficients of our explanatory variables and would go against the hypotheses we are testing. This caveat should be bourne in mind when interpreting our results.

Figure 1 shows the percentage of malaria cases according to the main source of lighting used by the household. The figure indicates that using electricity is associated with a higher incidence of malaria. In the case of the main source of lighting, 15\% of household members using electricity had experienced malaria in the last month compared to $13 \%$ of the household members using paraffin and tadooba and $7 \%$ using firewood. Differences in the percentages of malaria cases based on the main source of lighting are statistically significant. These descriptive statistics, while per se insufficient to derive causal claims, suggest that the relationship between energy sources and malaria incidence deserves further investigation. The multivariate analysis which follows will shed light on this.

\footnotetext{
${ }^{7}$ Interviews in both high and low income areas of Mbarara municipality, south-western Uganda, on the cause of malaria transmission show that $95 \%$ of the interviewed people recognized that mosquitoes are the main malaria vector, even though only one person named the microbe Plasmodium (Nuwaha, 2002).
} 
This is the version of the article accepted for publication in The European Journal of Development Research 28 (4), 521-535 published by Springer. Published version available from:

http://link.springer.com/article/10.1057/ejdr.2015.86

Accepted version downloaded from SOAS Research Online: http://eprints.soas.ac.uk/23439/

Figure 1: Percentages of malaria cases, by main source of lighting (rural households)

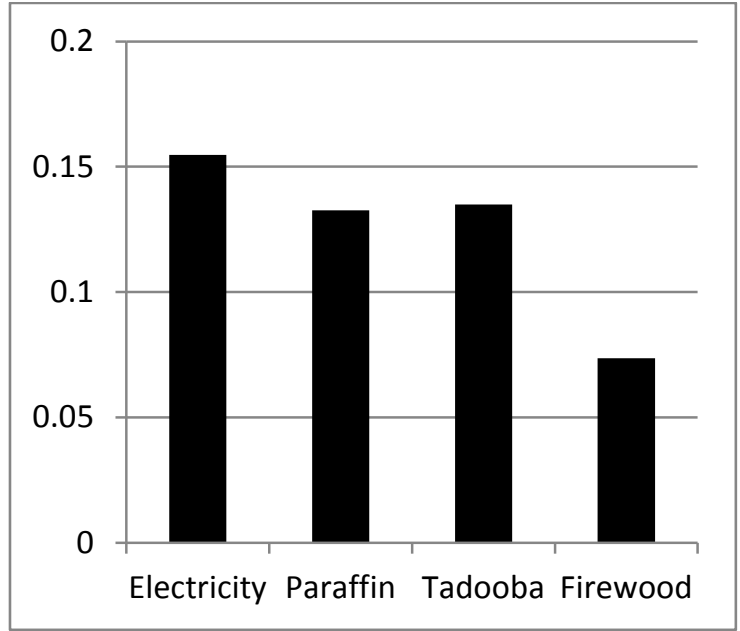

Notes: The data presented are simple correlations indicating that there might be a relationship between energy sources and malaria incidence. This potential relationship is investigated below with multivariate analysis to reach solid conclusions. Authors' elaboration from 'The Uganda National Household Survey, 2009-10'.

A first look at malaria incidence in the dataset shows that the number of household members having had malaria has a positive correlation with the income quintile classes, with the exception of the top quintile (Table 2). Thus, the number of individuals having malaria increases with the wealth of the households, but the differences from one quintile to the next are not particularly high nor statistically significant.

Table 2: Share and number of malaria cases, by income quintiles (rural households)

\begin{tabular}{lcccccc}
\hline Share and number of cases & $\begin{array}{c}\mathbf{1}^{\text {st }} \text { income } \\
\text { quintile }\end{array}$ & $\begin{array}{c}\mathbf{2}^{\text {nd }} \text { income } \\
\text { quintile }\end{array}$ & $\begin{array}{c}\mathbf{3}^{\text {rd }} \text { income } \\
\text { quintile }\end{array}$ & $\begin{array}{c}\mathbf{4}^{\text {th }} \text { income } \\
\text { quintile }\end{array}$ & $\begin{array}{c}\mathbf{5}^{\text {th }} \text { income } \\
\text { quintile }\end{array}$ & Total \\
\hline $\begin{array}{l}\text { Share of hh. members } \\
\text { having malaria (in \%) }\end{array}$ & 2.4 & 2.8 & 3.2 & 3.4 & 3.0 & 14.9 \\
$\begin{array}{l}\text { Number of hh. members } \\
\text { having malaria }\end{array}$ & 755 & 861 & 1,009 & 1,069 & 937 & 4,631 \\
\hline
\end{tabular}

Notes: Authors elaboration from 'The Uganda National Household Survey, 2009-10'.

Table 3 shows the share of households using various sources of energy; electricity is used for lighting in a fairly high share of households in the highest income quintile. Households in the income quintiles 1 to 4 mostly use paraffin lanterns and tadooba, which is anyway largely used by households in the highest income quintile. Firewood is 
This is the version of the article accepted for publication in The European Journal of Development Research 28 (4), 521-535 published by Springer. Published version available from:

http://link.springer.com/article/10.1057/ejdr.2015.86

Accepted version downloaded from SOAS Research Online: http://eprints.soas.ac.uk/23439/

used by almost $10 \%$ of the households, with the percentage being particularly high for those having the lowest income (30\%).

Table 3: Share of households using sources of energy for lighting and cooking, by income quintiles (rural households)

\begin{tabular}{lcccccc}
\hline & $\begin{array}{c}\mathbf{1}^{\text {st }} \text { income } \\
\text { quintile }\end{array}$ & $\begin{array}{c}\mathbf{2}^{\text {nd }} \text { income } \\
\text { quintile }\end{array}$ & $\begin{array}{c}\mathbf{3}^{\text {rd }} \text { income } \\
\text { quintile }\end{array}$ & $\begin{array}{c}\mathbf{4}^{\text {th }} \text { income } \\
\text { quintile }\end{array}$ & $\begin{array}{c}\mathbf{5}^{\text {th }} \text { income } \\
\text { quintile }\end{array}$ & Total \\
\hline Electricity & \multicolumn{7}{c}{ Main sources of lighting } \\
Paraffin lantern and tadooba & 0.46 & 0.64 & 1.13 & 2.21 & 9.62 & 2.71 \\
Firewood & 65.62 & 83.75 & 90.60 & 93.59 & 83.87 & 83.74 \\
Other & 30.33 & 11.45 & 4.97 & 1.52 & 0.97 & 9.74 \\
\hline
\end{tabular}

Notes: Authors elaboration from 'The Uganda National Household Survey, 2009-10'.

As will be clearer in the next section dealing with the empirical strategy and the presentation of the results, the 'treated' group is represented by 1) members of households using electricity as their main source of lighting and 2) female members of these households. We are aware that the number of households in the treatment groups is not very numerous as they represent a small share of the entire sample. This will not constitute a major problem since we will use data disaggregated at the individual level, as malaria related data are collected for each household member. ${ }^{8}$ For this reason the sample for model 1) consists of approximately 12,000 household members and the sample size for model 2 ) is 6,000 household members.

\section{Empirical strategy and main results}

In order to explore the link between the use of electricity and malaria and to assess the magnitude of this relationship, we estimate probit models. The dependent variable is dichotomous and takes on the value ' 1 ' if the household member stated to have had malaria in the last month and ' 0 ' otherwise. The estimates include cluster-adjusted

\footnotetext{
${ }^{8}$ At the same time, this estimation strategy will require that we produce cluster-adjusted standard errors.
} 
This is the version of the article accepted for publication in The European Journal of Development Research 28 (4),

521-535 published by Springer. Published version available from:

http://link.springer.com/article/10.1057/ejdr.2015.86

Accepted version downloaded from SOAS Research Online: http://eprints.soas.ac.uk/23439/

standard errors and the cluster unit is the household. We estimate several models in order to identify the channels through which malaria could be associated with the use of electric lights.

We define households using electricity for lighting as 'treated'. The treatment group is composed of all those household members who, as a consequence of using electricity as source of lighting, have a higher chance of changing their lifestyles, spending less time inside the dwelling in evening hours or have a higher chance of living in a place with a higher density of malaria vectors (both indoors and outdoors).

The model takes the following form:

$$
\text { Malaria } \left._{i}=a_{0}+b_{1} \text { (electricity for lighting }\right)_{i}+b_{i} X_{i}+e_{0 i}
$$

where the variable 'electricity for lighting' is a dummy. The ' $X$ ' is a vector of control variables i) per capita income (in logarithmic terms), ii) household size, iii) age of the household member, iv) type of dwelling (dummy variable taking on the value ' 1 ' if the household lives in a hut or barrack, ' 0 ' otherwise), v) material used for the roof of the house (' 1 ' if the roof is made with iron sheet, ' 0 ' otherwise), vi) whether the householder owns the house, vii) whether the household member uses a bed net soaked in mosquito repellent, viii) whether the household head, or the spouse, is literate, ix) asset variables (ownership of television/radio), $x$ ) type of toilet used by the household (' 1 ' if the household uses an uncovered toilet or bush, ' 0 ' otherwise), xi) a number of geographical dummies (not reported). 
This is the version of the article accepted for publication in The European Journal of Development Research 28 (4),

521-535 published by Springer. Published version available from:

http://link.springer.com/article/10.1057/ejdr.2015.86

Accepted version downloaded from SOAS Research Online: http://eprints.soas.ac.uk/23439/

The choice of control variables relies on the relations between the characteristics of the individual household and malaria incidence, that have been identified in existing studies. The logarithm of the household income is included as a proxy of the socio-economic status of the household. Income can influence numerous behavioural variables as well as determining the affordability of strategies to prevent malaria. Worrall et al.'s review of the evidence of the relationship between income and malaria incidence is inconclusive, even though it is claimed that better-off households are more likely to adopt malaria prevention strategies (Worrall et al., 2005). We include household size since we expect that members living in larger households are more likely to experience malaria (Huldén and McKitrick, 2013). Larger households may not have bed nets for all its members and may have a poorer sanitation system which is related to the growing incidence of the disease (Ajadi et al, 2012). In a similar vein, in coastal Kenya Snow et al. found that the occurrence of malaria among children sharing the same room is higher (Snow et al., 1998). On the contrary, Graves et al., in their study based in three Ethiopian regions, found no statistically significant relation between household size and malaria occurrence at the household member level (Graves et al., 2009).

We have also included variables related to the age of the household member and whether the head of the household, or the spouse, is literate. The link between age and malaria incidence has been investigated in some studies that found that older people are less likely to experience the disease (Kleinschmidt and Sharp, 2001). The inclusion of the literacy variable is motivated by the expectation that literate household heads might 
This is the version of the article accepted for publication in The European Journal of Development Research 28 (4),

521-535 published by Springer. Published version available from:

http://link.springer.com/article/10.1057/ejdr.2015.86

Accepted version downloaded from SOAS Research Online: http://eprints.soas.ac.uk/23439/

be more aware of the risks and of prevention strategies associated with malaria.

Variables related to housing quality are included because it is well established that housing conditions can have an impact on malaria (Guthmann et al., 2001). Poorly constructed houses or houses built with cheap materials have been associated with an increased risk of malaria as they might have open spaces between the roof and walls allowing access to malaria vectors. Likewise roofs constructed with traditional materials such as earth or thatch can increase the risk of malaria by 'providing access points, suitable resting places or breeding sites for malaria vectors' (Yamamoto, 2010). For the same reason, the type of toilet used could increase the risk of malaria, especially if the toilet is not covered since urine and feces attract mosquitoes. Floor material is not considered an important variable (Pålsson et al., 2004). At the same time being the owner of the dwelling might decrease the risk of malaria because house owners take more care of their homes, including repairing and sealing possible entry points for mosquitoes.

The use of repellent soaked bed nets is known to reduce malaria, while non-treated nets are not a powerful prevention tool for they tend to wear quickly and to have holes which provide entry points for malaria vectors. For example, in small-scale surveys carried out in Malawi and Kenya, between 80 and $90 \%$ of nets had holes (Holtz et al., 2002; Kachur et al., 1999). Television/radio ownership is expected to show that mass media and advertisements can increase the household awareness of malaria. Finally, a set of geographical dummies is included to prevent other factors related to the 
This is the version of the article accepted for publication in The European Journal of Development Research 28 (4),

521-535 published by Springer. Published version available from:

http://link.springer.com/article/10.1057/ejdr.2015.86

Accepted version downloaded from SOAS Research Online: http://eprints.soas.ac.uk/23439/

geography of the country and to the distribution of electricity from creating bias in the results.

The estimates are presented in Table 4. The strategy is to run the model first with a complete set of control variables and the whole sample of reported malaria cases by household members (Model 1). Next, we present results based only on malaria cases that are confirmed through a visit to a health practitioner (Model 2$)^{9}$. Subsequently, we run more parsimonious models that exclude economic explanatory variables for all reported cases of malaria (Model 3) and then only for those that are confirmed by visits to health practitioners (Model 4). The results across these four specifications indicate that electric lighting is associated with higher malaria incidence, with coefficients indicating that the probability of getting malaria increases somewhere between 10 and $23 \%$. In terms of statistical significance, the coefficients are significant at $10 \%$ level in 2 of our 4 models (Models 3 and 4), in one model significance is only 15\% (Model 1 ) and in another model the coefficient is not significant (Model 2).

The next set of regressions aims at verifying whether the effects of electricity on malaria incidence are different for female household members. Compared with men women spend more time in the dwelling, and if electricity increases the density of malaria vectors indoors female household members would be more likely to experience malaria. At the same time, if lifestyle changes are differentiated, increasing exposure for men, for example because they are more likely to be outdoors when electric lighting is available,

\footnotetext{
${ }^{9}$ As noted above, health practitioners is a broad category that includes for example traditional healers and does not imply reliable clinical testing.
} 
This is the version of the article accepted for publication in The European Journal of Development Research 28 (4), 521-535 published by Springer. Published version available from:

http://link.springer.com/article/10.1057/ejdr.2015.86

Accepted version downloaded from SOAS Research Online: http://eprints.soas.ac.uk/23439/

then the overall result by gender would be unclear. Estimates in Models 5 to 8 replicate the first set of regressions but include only the female household members. Thus, in Model 5 and in Model 7 the dependent variable is 'reported malaria cases' whereas in Model 6 and Model 8 the reported cases have been confirmed by health practitioners. The coefficient associated with the 'household using electricity for lighting' is significant at $10 \%$ in 1 (Model 7) and at 15\% in another two (Models 5 and 8) out of the 4 models, the size of the coefficients is only marginally affected by the focus on female members of the household, suggesting that the relationship between malaria and electric lighting is not strongly gendered.

For the sake of clarity, it is worth noticing that in the more parsimonious models Models 3, 4, 7 and 8 - the absence of economic independent control variables may indicate that the relationship between electricity use and malaria occurrence is ecological. Furthermore, in those models where malaria diagnosis has not been confirmed by a health practitioner - Models 3 and 7 - the coefficients could be suggesting that the use of electrification is associated with malaria-like illness rather than with malaria itself.

The log of per capita income shows a positive association with malaria and this result might appear somewhat surprising. We suspect that higher income might be associated with lifestyle changes that increase exposure to malaria vectors, e.g. spending more time outdoors. Furthermore, richer households might use more lighting for longer hours and have more light points, including more outdoor lights. That is, our interpretation is 
This is the version of the article accepted for publication in The European Journal of Development Research 28 (4), 521-535 published by Springer. Published version available from:

http://link.springer.com/article/10.1057/ejdr.2015.86

Accepted version downloaded from SOAS Research Online: http://eprints.soas.ac.uk/23439/

that the positive coefficient captures part of the effects of electric lighting, rather than genuine effects of income per se. Unfortunately, as discussed above, given the general nature of the multipurpose survey of our data, we cannot verify these details related to light use.

As expected, household size has a positive significance (albeit with a small coefficient), and we also find that the age of the household member has a negative correlation with the dependent variables. We did observe statistically significant associations between housing conditions and malaria occurrence in this study, with huts having a negative and significant association with malaria incidence (Ghebreyesus et al., 2000; Snow et al., 1998). The material of the roof and ownership of the house are not influential. Using treated bed nets soaked in mosquito repellent has a negative sign, although it is not statistically significant; the lack of statistical significance of the coefficients associated with the treated bed nets variable may be due to a number of reasons: i) the survey question on the use of a bed net refers only to last night, but has no information on regular use; ii) there is no observation on the condition of the bed nets which is often checked in field tests; iii) the survey refers to nets treated with repellent, rather than with insecticides that have been routinely used in field tests (e.g. Enayati and Hemingway, 2006; Phillips-Howard, et al., 2003).

The literacy variable of the household head and his spouse and tv/radio ownership are not associated with malaria occurrence. 
This is the version of the article accepted for publication in The European Journal of Development Research 28 (4), 521-535 published by Springer. Published version available from:

http://link.springer.com/article/10.1057/ejdr.2015.86

Accepted version downloaded from SOAS Research Online: http://eprints.soas.ac.uk/23439/ 
This is the version of the article accepted for publication in The European Journal of Development Research 28 (4), 521-535 published by Springer. Published version available from: http://link.springer.com/article/10.1057/ejdr.2015.86

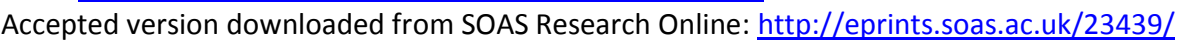

Table 4: Determinants of malaria infection for all household members (Models 1 to 4) and for women only (Models 5 to 8 )

\begin{tabular}{|c|c|c|c|c|c|c|c|c|}
\hline Independent variable & Model 1 & Model 2 & Model 3 & Model 4 & Model 5 & Model 6 & Model 7 & Model 8 \\
\hline $\begin{array}{l}\text { HH using electricity for } \\
\text { lighting }\end{array}$ & $\begin{array}{l}0.137 \\
(0.100)\end{array}$ & $\begin{array}{l}0.104 \\
(0.105)\end{array}$ & $\begin{array}{l}0.235^{* *} \\
(0.104)\end{array}$ & $\begin{array}{l}0.199 * \\
(0.109)\end{array}$ & $\begin{array}{l}0.174 \\
(0.125)\end{array}$ & $\begin{array}{l}0.100 \\
(0.130)\end{array}$ & $\begin{array}{l}0.249 * * \\
(0.126)\end{array}$ & $\begin{array}{l}0.180 \\
(0.130)\end{array}$ \\
\hline Per capita income in log. & $\begin{array}{l}0.086^{* * *} \\
(0.018)\end{array}$ & $\begin{array}{l}0.089 * * * \\
(0.018)\end{array}$ & & & $\begin{array}{l}0.081^{* * *} \\
(0.024)\end{array}$ & $\begin{array}{l}0.091 * * * \\
(0.023)\end{array}$ & & \\
\hline Household size & $\begin{array}{l}0.009 \\
(0.006)\end{array}$ & $\begin{array}{l}0.011^{*} \\
(0.006)\end{array}$ & $\begin{array}{l}0.006 \\
(0.006)\end{array}$ & $\begin{array}{l}0.008 \\
(0.006)\end{array}$ & $\begin{array}{l}0.015 * * \\
(0.007)\end{array}$ & $\begin{array}{l}0.017 * * \\
(0.007)\end{array}$ & $\begin{array}{l}0.012 * \\
(0.007)\end{array}$ & $\begin{array}{l}0.014 * * \\
(0.007)\end{array}$ \\
\hline $\begin{array}{l}\text { Age of the household } \\
\text { member }\end{array}$ & $\begin{array}{l}-0.009 * * * \\
(0.001)\end{array}$ & $\begin{array}{l}-0.009 * * * \\
(0.001)\end{array}$ & $\begin{array}{l}-0.009 * * * \\
(0.001)\end{array}$ & $\begin{array}{l}-0.009 * * * \\
(0.001)\end{array}$ & $\begin{array}{l}-0.009 * * * \\
(0.001)\end{array}$ & $\begin{array}{l}-0.009 * * * \\
(0.001)\end{array}$ & $\begin{array}{l}-0.009 * * * \\
(0.001)\end{array}$ & $\begin{array}{l}-0.009 * * * \\
(0.001)\end{array}$ \\
\hline $\mathrm{HH}$ lives in a hut & $\begin{array}{l}-0.171^{* * *} \\
(0.065)\end{array}$ & $\begin{array}{l}-0.194 * * * \\
(0.067)\end{array}$ & & & $\begin{array}{l}-0.168 * * \\
(0.080)\end{array}$ & $\begin{array}{l}-0.210 * * \\
(0.082)\end{array}$ & & \\
\hline $\begin{array}{l}\text { House roof made of iron } \\
\text { sheet }\end{array}$ & $\begin{array}{l}-0.050 \\
(0.052)\end{array}$ & $\begin{array}{l}-0.040 \\
(0.055)\end{array}$ & & & $\begin{array}{l}-0.080 \\
(0.066)\end{array}$ & $\begin{array}{l}-0.057 \\
(0.069)\end{array}$ & & \\
\hline HH owns the house & $\begin{array}{l}0.039 \\
(0.065)\end{array}$ & $\begin{array}{l}0.072 \\
(0.067)\end{array}$ & & & $\begin{array}{l}0.038 \\
(0.080)\end{array}$ & $\begin{array}{l}0.061 \\
(0.083)\end{array}$ & & \\
\hline $\begin{array}{l}\text { HH member uses treated } \\
\text { bed net }\end{array}$ & $\begin{array}{l}-0.030 \\
(0.041)\end{array}$ & $\begin{array}{l}-0.043 \\
(0.043)\end{array}$ & $\begin{array}{l}-0.018 \\
(0.041)\end{array}$ & $\begin{array}{l}-0.034 \\
(0.043)\end{array}$ & $\begin{array}{l}-0.030 \\
(0.049)\end{array}$ & $\begin{array}{l}-0.045 \\
(0.051)\end{array}$ & $\begin{array}{l}-0.025 \\
(0.049)\end{array}$ & $\begin{array}{l}-0.042 \\
(0.051)\end{array}$ \\
\hline $\begin{array}{l}\mathrm{HH} \text { head able to read and } \\
\text { write }\end{array}$ & $\begin{array}{l}0.057 \\
(0.038)\end{array}$ & $\begin{array}{l}0.044 \\
(0.040)\end{array}$ & & & & & & \\
\hline $\begin{array}{l}\mathrm{HH} \text { head spouse able to } \\
\text { read and write }\end{array}$ & & & & & $\begin{array}{l}0.006 \\
(0.046)\end{array}$ & $\begin{array}{l}-0.022 \\
(0.048)\end{array}$ & & \\
\hline HH owns radio or tv & $\begin{array}{l}0.002 \\
(0.036)\end{array}$ & $\begin{array}{l}0.001 \\
(0.038)\end{array}$ & & & $\begin{array}{l}0.017 \\
(0.043)\end{array}$ & $\begin{array}{l}0.017 \\
(0.046)\end{array}$ & & \\
\hline Uncovered toilet or bush & $\begin{array}{l}-0.010 \\
(0.040)\end{array}$ & $\begin{array}{l}0.006 \\
(0.042)\end{array}$ & & & $\begin{array}{l}0.030 \\
(0.049)\end{array}$ & $\begin{array}{l}0.047 \\
(0.051)\end{array}$ & & \\
\hline
\end{tabular}


This is the version of the article accepted for publication in The European Journal of Development Research 28 (4), 521-535 published by Springer. Published version available from: http://link.springer.com/article/10.1057/ejdr.2015.86

Accepted version downloaded from SOAS Research Online: http://eprints.soas.ac.uk/23439/

\begin{tabular}{|c|c|c|c|c|c|c|c|c|}
\hline District dummies & Yes & Yes & Yes & Yes & Yes & Yes & Yes & Yes \\
\hline \multirow[t]{2}{*}{ Constant } & $-1.597 * * *$ & $-1.614 * * *$ & $-0.427 * * *$ & $-0.378 * * *$ & $-1.680 * * *$ & $-1.825 * * *$ & $-0.620 * * *$ & $-0.623 * * *$ \\
\hline & $(0.291)$ & $(0.294)$ & $(0.175)$ & $(0.176)$ & $(0.379)$ & $(0.355)$ & $(0.203)$ & $(0.200)$ \\
\hline $\mathrm{N}$ & 12,522 & 11,073 & 12,547 & 11,096 & 6,730 & 5,940 & 6,741 & 5,950 \\
\hline
\end{tabular}

Notes: In Models 1, 3, 5 and 7, malaria reported cases is the dependent variable and includes cases that have not been confirmed by health practitioners. Malaria reported cases have been confirmed by health practitioners in Models 2, 4, 6 and 8 . District dummies refer to 80 rural districts. Cluster-adjusted robust standard errors are presented in parenthesis, the household being the cluster unit. 
This is the version of the article accepted for publication in The European Journal of Development Research 28 (4),

521-535 published by Springer. Published version available from:

http://link.springer.com/article/10.1057/ejdr.2015.86

Accepted version downloaded from SOAS Research Online: http://eprints.soas.ac.uk/23439/

\section{Conclusions and policy implications}

Rural electrification is a policy priority for many developing countries and electrifying urban and rural areas contributes to socioeconomic development. The increase in energy consumption, as a consequence of electrification projects, has resulted in electricity being used for lighting as well as for entertainment (television, charging mobile telephones, using radio). Electricity use has proved to be beneficial for school attendance, for the quality of health services and for reducing indoor air pollution from biomass use. While these positive consequences of access to electricity have attracted much attention, little is known about the unintended negative health effects of rural electrification.

In this study we have presented evidence - through descriptive statistics and multivariate empirical analysis - showing that electricity used for lighting purposes is associated with a higher incidence of malaria in rural Uganda. The result must be taken with considerable reserve since the findings are not robust across all the multivariate specifications; the coefficient associated with the use of electric lighting is always positive, - statistically significant in 3 models, marginally insignificant in 3 models and non-significant in 2 models. As discussed above, given the plausible presence of some measurement of error in the dependent variable (that would diminish statistical significance) and the fact that we do not have the best variables to describe the actual use of electric lighting by each household member (as compared to access to electricity at the household level) the result provides a strong indication of an existing relationship. 
This is the version of the article accepted for publication in The European Journal of Development Research 28 (4),

521-535 published by Springer. Published version available from:

http://link.springer.com/article/10.1057/ejdr.2015.86

Accepted version downloaded from SOAS Research Online: http://eprints.soas.ac.uk/23439/

To our knowledge this study represents the first attempt, using a large scale survey, to estimate whether the use of electricity might influence the spread of malaria.

We chose to focus on rural Uganda as this country has a relative low share of electrified households, a number of projects to improve electricity penetration and, at the same time, the incidence of malaria is still very high. These are conditions that - often in less extreme forms - characterise several Sub-Saharan countries.

The regression coefficients corroborate our hypothesis that electricity can increase 'vector density' and 'exposure', ultimately leading to higher malaria incidence. It should be noted, though, that our results refer to households in rural Uganda and cannot be easily generalised and we cannot be sure of whether the hypothesised association between electrification and malaria is valid elsewhere in Sub-Saharan Africa. In addition, in order to test these hypotheses more rigorously, ad-hoc surveys should be undertaken with a panel of households. The survey we used does not specifically focus on malaria with the drawback that the number of questions related to malaria is small and the malaria indicator is not the most precise since it is not corroborated by clinical diagnoses. Equally important, questions pertaining to electric light equipment and use are limited (e.g. the survey does not include information on how much time each household member is exposed to electric lighting).

The purpose of this study is to raise the awareness of those working in developing projects about the potential existence of an electricity-malaria link. We trust that this article will contribute to shedding light on this neglected implication of electrification 
This is the version of the article accepted for publication in The European Journal of Development Research 28 (4), 521-535 published by Springer. Published version available from:

http://link.springer.com/article/10.1057/ejdr.2015.86

Accepted version downloaded from SOAS Research Online: http://eprints.soas.ac.uk/23439/

and encourage epidemiologists and economists to carry out ad-hoc studies based on more detailed and reliable data. Such studies should focus also on areas that go beyond rural Uganda.

At the policy level, our results suggest that electrification projects should be accompanied by targeted strategies to combat malaria. While the details of such strategies will have to be the elaborated on the basis of specific studies, they can include a focus on mosquito nets and screens together with their periodical maintenance and education campaigns on the positioning and use of electric lighting appliances.

\section{References}

Asl, H. M., Motabar, M., Zamani, G., Naserinejad, D., Vatandoost, H. (2003). A CaseControl Study of Determinative Factors on Malaria Morbidity in Minab, Jask and Roodan Counties, in Hormozgan Province, Southern Iran, 2001. Iranian Journal of Public Health 32: 14-18.

Ajadi, K. O., Olaniran, H. D., Alabi, F. M., Adejumobi, D. O. (2012). Incidence of malaria among various socio-economic households. Greener Journal of Medical Sciences 2 (3): 51-63

Barghini, A. and de Medeiros, B. A. S. (2010). Artificial Lighting as a Vector Attractant and Cause of Disease Diffusion. Environmental Health Perspectives 118: 1503-1506.

Barnes, B.R., Mathee, A., Krieger, L., Shafritz, L., Favin, M., Bruce, N., Gilson, L. (2004). Testing selected behaviors to reduce indoor air pollution exposure in young children. Health Educ. Res. 19: 543-550.

Barrett, J. R. jr., Huber, R.T., Harwood, F.W. (1973). Selection of lamps for minimal insect attraction. Trans. Am. Soc. Ag. Eng. 17(4): 710-711.

Barrett, J. R. jr., Killough, R.A., Hartsok, J.G. (1974). Reducing insect problems in lighted areas. Trans. Am. Soc. Ag. Eng. 18(2): 329-30. 
This is the version of the article accepted for publication in The European Journal of Development Research 28 (4),

521-535 published by Springer. Published version available from:

http://link.springer.com/article/10.1057/ejdr.2015.86

Accepted version downloaded from SOAS Research Online: http://eprints.soas.ac.uk/23439/

Biran, A., Smith, L., Lines, J., Ensink, J., Cameron, M. (2007). Smoke and malaria: are interventions to reduce exposure to indoor air pollution likely to increase exposure to mosquitoes? Transactions of the Royal Society of Tropical Medicine and Hygiene. 101: 1065-1071.

Chong, A. and La Ferrara, E. (2009). Television and Divorce: Evidence from Brazilian Novelas. Journal of European Economic Association. 7(2-3): 458-468.

Erhart, A., Thang, N., Nguyen, Q. H., Toi, L., Hung, L., Tuy, T., Cong, L., Speybroeck, N., Coosemans, M. and D'Alessandro, U. (2004). Forest malaria in Vietnam: a challenge for control. Am. J. Trop. Med. Hyg. 70(2): 110-118

Enayati, Ahmad Ali, and Janet Hemingway (2006). Pyrethroid insecticide resistance and treated bednets efficacy in malaria control. Pesticide biochemistry and physiology 84(2): $116-126$.

Ezzati, M., Saleh, H., Kammen, D.M. (2000). The contributions of emissions and spatial microenvironments to exposure to indoor air pollution from biomass combustion in Kenya. Environ. Health Perspect. 108: 833-839.

Ghebreyesus, T.A., Haile, M., Witten, K.H., Getachew, A., Yohannes, M., Lindsay, S.W. (2000). Household risk factors for malaria among children in the Ethiopian highlands. Trans R Soc Trop Med Hyg. 94: 17-21.

Gil, L. H. S., Tada, M. S., Katsuragawa, T. H., Ribolla, P. E. M., Pereira da Silva, L. (2007). Urban and suburban malaria in Rondônia (Brazilian Western Amazon) II. Perennial transmissions with high anopheline densities are associated with human environmental changes. Mem Inst Oswaldo Cruz, Rio de Janeiro.

Graves, P. M., F. O. Richards, J. Ngondi, et al. (2009). Individual, household and environmental risk factors for malaria infection in Amhara, Oromia and SNNP regions of Ethiopia. Transactions of the Royal Society of Tropical Medicine and Hygiene 103(12): 1211-1220.

M. Grimm, R. Sparrow and L. Tasciotti (2015). Does electrification spur the fertility transition? Evidence from Indonesia. Demography. 52(5).

Guthmann, J.P., Hall, A.J., Jaffar, S., Palacios, A., Lines, J., Llanos-Cuentas, A. (2001). Environmental risk factors for clinical malaria: a case-control study in the Grau region of Peru. Trans R Soc Trop Med Hyg. 95: 577-83. 
This is the version of the article accepted for publication in The European Journal of Development Research 28 (4),

521-535 published by Springer. Published version available from:

http://link.springer.com/article/10.1057/ejdr.2015.86

Accepted version downloaded from SOAS Research Online: http://eprints.soas.ac.uk/23439/

Holtz, T. H., Marum, L. H., Mkandala, C., Chizani, N., Roberts, J. M., Macheso, A., Parise, M. E., Kachur, S.P. (2002). Insecticide-treated bednet use, anaemia, and malaria parasitaemia in Blantyre district, Malawi. Trop Med Int Health. 7: 220-230.

Huldén, L. and McKitrick, R. (2013). Average household size and the eradication of malaria. Journal of the Royal Statistical Society. Series A, DOI: 10.1111/rssa.12036

International Energy Agency (2011), World Energy Outlook 2011.

Jawara, M., Pinder, M., Drakeley, C. J., Nwakanma, D. C., Jallow, E., Bogh, C . (2008). Dry season ecology of Anopheles gambiae complex mosquitoes in the Gambia. Malaria Journal. 7.

Kachur, S. P., Phillips-Howard, P. A., Odhacha, A. M., Ruebush, T. K., Oloo, A. J., Nahlen, B. L. (1999). Maintenance and sustained use of insecticide-treated bed nets and curtains three years after a controlled trial in western Kenya. Trop Med Int Health. 4: 728-735.

Kengeya-Kayondo, J., Seeley, J., Kajura-Bajenja, E., Kabunga, E., Mubiru, E., Sembajja, F., Mulder, D. (2004). Recognition, treatment seeking behaviour and perception of cause of malaria among rural women in Uganda. Acta Tropica. 58: 267-273.

Kleinschmidt, I. And Sharp, B (2001). Patterns in age-specific malaria incidence in a population exposed to low levels of malaria transmission intensity. Tropical Medicine \& International Health 6(12): 986-991.

Konradsen, F., Amerasinghe, P., van der Hoek, W., Amerasinghe, F., Perera, D., Piyaratne, M. (2003). Strong association between house characteristics and malaria vectors in Sri Lanka. Am. J. Trop. Med. Hyg. 68: 177-181.

Lee, H. I., Seo, B. Y., Shin, E. H., Burkett, D. A., Lee, J. K., Shin, Y. H. (2009). Efficacy evaluation of Nozawa-style black light trap for control of anopheline mosquitoes. Korean Journal Parasitol. 47:159-165.

Louzada, F. M., Inácio, A. M., Souza, F. H. M. and Moreno, C. R. C. (2004). Exposure to light versus way of life: Effects on sleep patterns of a teenager - Case report. Chronobiology International. 3: 497-499.

Lynch, K. L., Beach, R., Asamoa, K., Adeya, G., Nambooze, J. and Janowsky E. (2010). President's Malaria Initiative, Rapid Assessment Report.

Ministry of Energy and Mineral Development (2002). The Energy Policy for Uganda.

Noor, A. M., Alegana, V. A., Gething, P. W., Tatem A. J., Snow, R. W. (2008). Using remotely sensed night-time light as a proxy for poverty in Africa, Popul Health Metr; [Online 15 October 2011]. 
This is the version of the article accepted for publication in The European Journal of Development Research 28 (4), 521-535 published by Springer. Published version available from:

http://link.springer.com/article/10.1057/ejdr.2015.86

Accepted version downloaded from SOAS Research Online: http://eprints.soas.ac.uk/23439/

Nuwaha, F. (2002). People's perception of malaria in Mbarara, Uganda. Tropical Medicine and International Health. 7: 462-470.

Paul, R. E., Packer, M. J., Walmsley, M., Lagog, M., Ranford-Cartwright, L. C., Paru, R. and Day, K. P. (1995). Mating patterns in malaria parasite populations of Papua New Guinea. Science. 269: 1709-1711.

Pålsson, K., Jaenson, T.G., Dias, F., Laugen, A. T., Bjorkman, A. (2004). Endophilic Anopheles mosquitoes in Guinea Bissau, West Africa, in relation to human housing conditions. Journal of Med Entomol. 41:746-52.

Pellegrini, L. and Tasciotti, L. (2012). Rural electrification now and then: comparing contemporary challenges in developing countries to the United States' experience in retrospect. Forum of Development Studies 2012. 1-24.

Phillips-Howard, P. A., Nahlen, B. L., Kolczak, M. S., et al. (2003). Efficacy of permethrintreated bed nets in the prevention of mortality in young children in an area of high perennial malaria transmission in western Kenya. The American journal of tropical medicine and hygiene, 68(4 suppl), 23-29.

PMI (2012). Country Profile: Uganda. Washington, DC. President's Malaria Initiative (PMI).

Rural Electrification Agency (2006). Strategic Plan2005/06 - 2011/12.

Seyoum, A., Pålsson, K., Kung'a, S., Kabiru, E.W., Lwande, W., Killeen, G.F., Hassanali, A., Knols, B.G.J. (2002). Traditional use of mosquito-repellent plants in western Kenya and their evaluation in semi-field experimental huts against Anopheles gambiae: ethnobotanical studies and application by thermal expulsion and direct burning. Trans. R. Soc. Trop. Med. Hyg. 96: 225-231.

Shiff, C. J., Minjas, J. N., Hall, T., Hunt, R. H., Lyimo, S. and Davis, J. R. (2008). Malaria infection potential of anopheline mosquitoes sampled by light trapping indoors in coastal Tanzanian villages. Medical and Veterinary Entomology. 9 (3): 256-262.

Snow, R.W., Peshu, N., Forster, D., Bomu, G.,Mitsanze, E., Ngumbao, E. (1998). Environmental and entomological risk factors for the development of clinical malaria among children on the Kenyan coast. Trans R Soc Trop Med Hyg. 92: 381-385.

Suárez-Mutis, M. C., Fé, N. F., Alecrim, W., Coura, J. R. (2009). Night and crepuscular mosquitoes and risk of vector-borne diseases in areas of piassaba extraction in the middle Negro River basin, state of Amazonas, Brazil. Mem Inst Oswaldo Cruz. 104: 1117. 
This is the version of the article accepted for publication in The European Journal of Development Research 28 (4),

521-535 published by Springer. Published version available from:

http://link.springer.com/article/10.1057/ejdr.2015.86

Accepted version downloaded from SOAS Research Online: http://eprints.soas.ac.uk/23439/

Taylor, B (1997). Malaria transmission - mosquitoes, humans and their behavior. Antenna. 18: 18-22.

Thang, N. D., Erhart, A., Speybroeck, N., Hung, L. X., Thuan, L. K., Hung, C. T., Van Ky, P., Coosemans, M. and D'Alessandro, U. (2008). Malaria in central Vietnam: analysis of risk factors by multivariate analysis and classification tree models. Malaria Journal. 7.

Tirados, I., Costantini, G., Gibson, G., Torr, S. J. (2006). Blood-feeding behaviour of the malaria mosquito Anopheles arabiensis: implications for vector control. Medical and Veterinary Entomology. 20: 425-437.

Torres-Duque, C., Maldonado, D., Perez-Padilla, R., Ezzati, M. and Viegi, G. (2007). Biomass Fuels and Respiratory Diseases. A Review of the Evidence. American Thoracic Society. 5: 577-590.

Tsuyuoka R, Wagatsuma Y, Makunike B. (2010). The knowledge and practice on malaria among community members in Zimbabwe. Cent African Journal of Medicine. 47: 7-14.

Ugandan Ministry of Health (2005). Uganda Malaria Control Strategic Plan 2005/06 2009/10. Malaria Control Programme.

UNDP (2011). Human development report. Sustainability and equity: a better future for all.

van der Hoek, W., Konradsen, F., Dijkstra, D.S., Amerasinghe, P. H., Amerasinghe F. P. (1998). Risk factors for malaria: A microepidemiological study in a village in Sri Lanka. Transactions of the Royal Society of Tropical Medicine and Hygiene. 92:265-269.

Winther, T. (2011). The Impact of Electricity: Development, Desires and Dilemmas.

Wright, K. P., Gronfier, C., Duffy, J. F. and Czeisler, C. A. (2005). Intrinsic period and light intensity determine the phase relationship between melatonin and sleep in humans. Journal of Biological Rhythm. 20: 168-177.

World Bank (2008). The Welfare Impact of Rural Electrification: A Reassessment of the Costs and Benefits An IEG Impact Evaluation. The World Bank, Washington, D.C.

World Health Organization (2012). World malaria report 2012, WHO Press, Geneva, Switzerland.

World Health Organization (2010). World Malaria Report, 2010, World Health Organization, Geneva.

Worrall, E., Basu, S. and Hanson, K. (2005). Is malaria a disease of poverty? A review of the literature. Tropical Medicine \& International Health 10(10): 1047-1059. 
This is the version of the article accepted for publication in The European Journal of Development Research 28 (4), 521-535 published by Springer. Published version available from:

http://link.springer.com/article/10.1057/ejdr.2015.86

Accepted version downloaded from SOAS Research Online: http://eprints.soas.ac.uk/23439/

Yamamoto, S., Louis, V.R., Sié, A. and Sauerborn, R. (2010). Household risk factors for clinical malaria in a semi-urban area of Burkina Faso: a case-control study. Transactions of the Royal Society of Tropical Medicine and Hygiene. 104: 61-65.

Ye, Y., Hoshen, M., Louis, V., Seraphin, S., Traore, I., Sauerborn, R. (2006). Housing conditions and Plasmodium falciparum infection: protective effect of iron-sheet roofed houses. Malaria JnI. 5. 